\title{
KARAKTER MANUSIA DALAM PERSPEKTIF AL-QUR'AN SURAT LUKMAN
}

\author{
Ahmad Helwani Syafi'i \\ Muhammad Syaoki \\ Universitas Muhammadiyah Mataram \\ okiepluralist@gmail.com \\ helwani.ahmad@gmail.com
}

\begin{abstract}
The character education is the part is very important in human life in order to form of private men to form personal morality in the social life, hence is needed step in business the search for values and the concept of character education based it Alquran that is a source of the truth in excellence. This study aims to to uncover the concept of character education in a lukman with a focus research which includes: 1) a human character in the Alquran letter Lukman; 2) the value of a character in alquran a letter Lukman, 3 ) the process planting the value of a character that is in Alquran a letter of Lukman.Based on the research done it is found that; 1 a) human character in the Alquran a letter Lukman includes: a ) muhsinin, b ) piety, c) concerns high, d) humble, e) arrogant, f) and they favors; 2 . The value of a character in a lukman includes: a) the value faith / call, b) the value birrul waalidain (kind to older people), c) the value thanks, d) wise, e) the value patient; 3 . The process of planting the value of a character in a letter lukman.
\end{abstract}

Keywords: Character, Concept, Humatinity 


\section{A. Pendahuluan}

Sebagai awal pembahasan dalam penelitian ini, ada dua aspek yang menurut penulis sangat relevan untuk dikemukakan, yaitu: pertama, realitas empirik (das sein)—ialah fenomena karakter manusia yang saat sekarang ini sedang menimpa bangsa. Kedua, realitas teoritik (das sollen), yaitu beberapa hasil penelitian terdahulu yang relevan untuk dikaji, khususnya penelitian yang erat kaitannya dengan tema karakter.

Melihat carut-marutnya kondisi moral bangsa, karakter manusia menjadi alternatif utama untuk mengatasi permasalahan tersebut. Dengan begitu karakter manusia menjadi sebuah tema yang urgen pelaksanaannya bagi pembangunan bangsa-sebab karakter menjadi tolak ukur keberhasilan suatu bangsa. karakter menjadi program bangsa yang wajib dilaksanakan oleh bangsa Indonesia.

Berdasarkan realitas empirik tersebut, maka upaya penanaman nilai-nilai karakter sudah menjadi tanggung jawab bersama dan merupakan suatu yang tidak mudah. Karena dengan melahirkan lulusan yang berkarakter mulia serta mengaplikasikannya dalam kehidupan nyata, maka disanalah suatu lembaga ataupun sebuah bangsa dianggap berhasil dalam melahirkan generasi bangsa yang berkualitas, bermoral, beriman, dan berkarakter tinggi. Jika demikianlalu karakter yang bagaimana sehingga suatu lembaga atau bangsa bisa di anggap berhasil dalam melahirkan autput yang baik. Hal inilah yang sangat menarik penulis untuk mengkaji realitas empirik tersebut secara mendalam.

\section{B. Karakter}

Secara etimologi, istilah karakter berasal dari bahasa Latin character, yang berarti: watak, tabiat, sifat-sifat kejiwaan, budi pekerti, kepribadian dan akhlak. Istilah karakter juga diadopsi dari bahasa Latin kharakter, kharasisen, dan kharaxyang berarti tool for marking, to engrave, dan pointed stake. ${ }^{1}$ Dalam bahasa Inggris diterjemahkan menjadicharacter berarti tabiat, budi pekerti, watak. ${ }^{2}$ Dalam bahasa Arab, karakter diartikan sebagai khuluq, sajiyyah, thab'u (budi pekerti, tabiat atau watak). Kadang juga diartikan

\footnotetext{
$1 \quad$ Wyne dalam Musfah, Pendidikan Karakter: Sebuah Tawaran Model Pendidikan Holistik, Integralistik, (Jakarta, Prenada Media, 2011), 127.

2 John Echols, Kamus Populer, (Jakarta: Rineka Cipta Media, 2005), 37.
} 
syakhsiyyah yang artinya lebih dekat dengan personality (kepribadian). ${ }^{3}$

Secara terminologi (istilah), karakter diartikan sebagai sifat manusia pada umumnya yang bergantung pada faktor kehidupannya sendiri. Karakter adalah sifat kejiwaan, akhlak atau budi pekerti yang menjadi ciri khas seseorang atau sekelompok orang. Pengertian karakter dengan makna akhlak ini sejalan dengan pandangan al-Ghazali yang mengatakan bahwa karakter (akhlak) adalah sesuatu yang bersemayam dalam jiwa yang dengannya timbul perbuatanperbuatan dengan mudah tanpa dipikirkan terlebih dahulu. ${ }^{4}$

Adapun Menurut Mansur Muslich, karakter adalah suatu sistempenanamannilai-nilaikarakter kepada warga sekolah yang meliputi komponen pengetahuan, kesadaran atau kemauan, dan tindakan untuk melaksanakan nilai-nilai tersebut, baik terhadap Tuhan Yang Maha Esa (YME), diri sendiri, sesama, lingkungan, maupun kebangsaan

3 Aisyah Boang dalam Supiana, Mozaik Pemikiran Islam: Bunga Rampai Pemikiran Pendidikan Indonesia, (Jakarta: Dirjen Dikti, 2011),5.

4 Abdul Hamid,al-Ghazali, Ihya 'Ulum al-din, (Mesir: Daar at-Taqwa, jld 2), 94. sehingga menjadi manusia insan kamil. ${ }^{5}$

1. Proses penanamannilai karakter

Membentuk karakter pada diri anak memerlukan suatu tahapan yang dirancang secara sistematis dan berkelanjutan. Sebagai individu yang sedang berkembang, anak memiliki sifat suka meniru tanpa mempertimbangkan baik atau buruk. Hal ini didorong oleh rasa ingin tahu dan ingin mencoba sesuatu yang diminati yang kadangkala muncul secara spontan. Sikap jujur yang menunjukkan kepolosan seorang anak merupakan ciriyangjuga dimilikinya. Kehidupan yang dirasakan anak tanpa beban menyebabkan anak tampil selalu riang dan dapat bergerak serta berkreatifitas secara bebas. Dalam aktivitas ini, anak cenderung menunjukkan sifat ke-aku-annya

2. Nilai-nilai pendidikan karakter

Nilai diartikan sebagai seperangkat moralitas yang paling abstrak dan seperangkat keyakinan atau perasaan yang diyakini sebagai suatu idealitas dan memberikan corak khusus pada pola pemikiran,

5 Masnur Muslich, Pendidikan karakter: Menjawab Tantangan Krisis Multidimensional, (Jakarta: Bumi Aksara, 2011), 84. 
perasaan, dan perilaku.Misalnya nilai ketuhanan, nilai kemanusiaan, nilai keadilan, nilai moral, baik itu kebaikan maupun kejelekan. ${ }^{6}$

Menurut Nurcholis Madjid, ${ }^{7}$ dalam ajaran Islam, ada nilai (a) robbaniyah seperti: iman, islam, ihsan, takwa, ikhlas, tawakkal, syukur dan sabar. dan (b) insaniyah, seperti shilaturrahmi, (shilaturrahim), persaudaraan (ukhuwah), persamaan (al-musawat), adil ('adl), baik sangka (husnadhonni), rendah hati (tawadlu'), tepat janji (wafa'), lapang dada (insyirah), perwira ('iffah), hemat (qawamiyah), dan dermawan (munfiqun).

\section{ModelPendekatanKarakter}

Dalam penelitian (karakter manusia dalam persepektif AlQur'an surat Lukman) menekankan pada pengungkapan makna teks dengan persepektif karakter manusia. Penelitian ini merupakan penelitian kepustakaan (Library Reseach), yaitu suatu cara kerja tertentu yang bermanfaat untuk mengetahui pengetahuan ilmiah dari

6 Muslim Nurdin dkk., Moral dan Kognisi Islam, ( Bandung: Alfabeta, 2008), 209.

7 Nurcholis Madjid dalam Ridwan, Pengembangan Nilai-nilai Islami dalam Pembelajaran PAI di SMA, (El-Hikam Press, 2013),23. suatu dokumen yang dikemukakan oleh ilmuan di masa lampau dan masa sekarang. ${ }^{8}$ Jenis penelitian ini adalah penelitian kualitatif sehingga menghasilkan data deskriptif berupa katakata, catatan yang berhubungan dengan makna, nilai dan pengertian.

Dalam penelitian ini penulis menggunakan metode tafsir dengan pendekatan maudu'i (tematik) dan tahlili (analitik). Metode maudu'i adalah membahas ayat-ayat alQur'an dengan tema atau judul yang sudah ditentukan. ${ }^{9}$ Pada penelitian ini yang menjadi objek penelitian adalah al-Qur'an surat Lukman. Sedangkan sumber datanya - peneliti membaginya dalam dua jenis, yaitu sumber primer dan sumber skunder.

Teknik pengumpulan data yang digunakan dalam penelitian ini adalah teknik dokumentasi ${ }^{10}$, yaitu teknik pengumpulan data dengan cara menyelidiki. Penulis menggunakan

8 Kaelan, Metode Penelitian Kualitatif Bidang Filsafat (Yogyakarta: Paramadina, 2005), 250.

9 Abd. al-Hayy Al-Farmawi, Metode Tafsir Maudu'iy, Suatu Pengantar, Terj: Suryan A. Jamrah, Cet- 1, (Jakarta:Raja Grafindo, 1994), 36.

10 Mestika Zeid, Metode Penelitian Untuk Skripsi Dan Tesis Bisnis, (Jakarta: Raja Grafindo Persada, 2000), 9. 
metode dokumentasi dalam melakukan pengumpulan data.

\section{Nilai dan Karakter Manusia}

\section{Karakter Manusia}

1) Muhsinin

Mereka adalah orang-orang yang senantiasa memperbaiki amal perbuatan dalam mengikuti syari'at Nabi.Makamerekamendirikanshalat fardhu sesuai dengan ketentuanketentuan dan waktu-waktunya, disamping melengkapinya dengan sholat-sholat sunnah, baik rawatib (sholatsunnatyangmengiringisholat fardhu) atau ghair rawatib (sholat sunnat yang diluar sholat rawatib). Mereka senantiasa menunaikan zakat yang menjadi kewajiban bagi mereka untuk diberikan kepada yang berhak. Mereka senantiasa menyambungkan tali persaudaraan dan kekerabatan serta meyakini adanya balasan di negeri akhirat nanti. Mereka berharap kepada Allah agar mereka mendapatkan pahala atas amal-amal shalih yang mereka kerjakan, dengan tidak menampakkan sikap riya' sedikitpun, mereka tidak menginginkan balasan dan rasa terimakasih dari manusia. ${ }^{11}$

11 Ibn Katsir, Tafsir Ibn Katsir, (bairutlebanun: daar al-kutb al-alamiah) t.th. 406.
Kata al-Muhsinin adalah bentuk jamak dari muhsin. Bagi seorang manusia, sifat ini menggambarkan puncak kebaikan yang dapat dicapai. Yaitu pada saat ia memandang dirinya pada diri orang lain, sehingga ia memberi untuk orang lain itu apa yang seharusnya ia ambil sendiri. ${ }^{12}$ Sedang ihsan terhadap Allah Swtkarena itu pula, ihsan seseorang manusia terhadap sesama manusia adalah, bahwa ia tidak meihat lagi dirinya dan hanya melihat orang lain. Siapa yang melihat dirinya pada posisi kebutuhan orang lain dan tidak melihat dirinya pada saat beribadah kepada Allah Swt, maka dia itulah yang dinamai muhsin, dan ketika itu dia telah mencapai puncak dalam segala amalnya.

2) Kesalehan

Kemudian pada ayat ke-8 Allah menjanjikan balasan syurga bagi orang yang beriman kemudian dengan keimanannya itu mereka berbuat kebaikan, beramal sholeh dengan ada tanpa mengharapkan balasan dari apa yang ia lakukan, ikhlas dalam beramal, maka bagi orang-orang yang memiliki sifat atau karakter yang demikian itu

12 Quraish Shihab, Tafsir al-Misbah; Pesan, Kesan dan Keserasian al-Qur'an, (Jakarta: Lentera Hati, 2002),11. 
Allah masukkan kedalam syurganya dan akan kekal didalamnya.

Sebagaimanakebiasaanal-Qur'an menggandengkan hal-hal yang serasi atau sama sekali bertolak belakang, maka disini setelah ayat-ayat yang lalu membicarakan kedurhakaan manusia, serta ancaman dan sanksi yang menantinya, kini diutarakan janji ganjaran yang menanti yang patuh kepada Allah Swt. Allah berfirman: Sesungguhnya orang-orang yang beriman dengan keimanan yang benar dan membuktikan kebenaran imannya dengan mengerjakan amalamal saleh, bagi mereka surgasurga yang penuh kenikmatan. Di sana mereka tinggal dengan penuh kebahagiaan dalam keadaan kekal didalamnya. Itu adalah janji Allah yang benar yang tidak mungkin

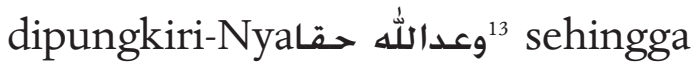
pasti sesuai dengan kenyataan yang tidak pernah akan meleset dan peristiwa yang akan terjadi pasti terjadi. $^{14}$

\section{3) Rendahhati}

Kemudian pada ayat ke 18-19 adalah merupakan larangan untuk memalingkan muka dan berjalan dimuka bumi ini dengan sombong,

13 Quraish Shihab, Tafsir alMisbah...,117.

14 Ibn Katsir, Tafsir Ibn Katsir, (BairutLebanun: Daar al-kutb al-Alamiah) t.th. 407. hal ini menandakan bahwasanya didalam ayat ini terkandung ajaran untuk bersifat lemah lembut dan sopan santun karena apabila suatu larangan untuk mengerjakannya sesuatu maka terkandung perintah untuk meninggalkan dan mengerjakan lawanan dari perbuatan tersebut.

\section{Nilai karakter}

a. Nilai Tauhid

Kemudian dalam ayat ke-13 terdapat nilai karakter tentang ketauhidan, karena sebagian pesan dari Lukman kepada anaknya adalah laranganuntukmenyekutukan Allah. Lukman memulai nasihatnya dengan menekankan perlunya menghindari syirik/mempersekutukan Allah. Larangan ini sekaligus mengandung pengajaran tentang wujud dan keesaan Tuhan. Bahwa redaksi pesannya berbentuk larangan, jangan mempersekutukan Allah untuk menekan perlunya meninggalkan sesuatu yang buruk sebelum melaksanakan yang baik. Memang "At-Takhliyah Muqaddamun Ala At-Tahliyah" (menyingkirkan keburukan lebih utama daripada menyandang perhiasan). ${ }^{15}$

b. Nilai birrul walidain

15 Quraish Shihab, Tafsir alMisbah...,127. 
Pada ayat 14 Surah Luqman mengandung nilai pendidikan karakter bersikap dan berperilaku yang menunjukkan ketaatan dan berbuat baik kepada kedua orang tua (birrulwãlidain) dengan jalan bersyukur kepada Allah dan bersyukur kepada kedua orang tua dengan jalan berbuat baik kepada kedua orang tua ditunjukkan dengan sikap lemah lembut, menghindari kekerasan perilaku dan tutur kata, ikut meringankan beban atau tanggungan orang tua

c. Nilai syukur

Pada ayat 12 Surah Luqman terdapat nilai karakter yaitu kata syukur yakni bersyukur kepada Allah, Ayat tersebut menyatakan: dan sesungguhnya kami yang maha perkasa dan bijakasana telah menganugrahkan dan mengajarkan juga mengilhami hikmah kepada Lukman, yaitu: "bersyukurlah kepada Allah, dan barang siapa yang bersyukur kepada Allah, maka sesungguhnya ia bersyukur untuk kemaslahatan dirinya sendiri; dan barang siapa yang kufur yakni tidak bersyukur, maka yang merugi adalah dirinya sendiri. Dia sedikitpun tidak merugikan Allah, sebagimana yang bersyukur tidak menguntungkanNya, karena sesungguhnya Allah maha kaya tidak butuh pada apapun, lagi maha terpuji oleh makhluk dilangit dan di bumi". ${ }^{16}$

d. Nilai sabar

Disini Quraish Shihab menafsirkan makna dari menyuruh mengerjakan ma'ruf, mengandung pesan untuk mengerjakannya, karena tidaklah wajar menyuruh orang sebelum diri sendiri mengerjakannnya. Demikian juga melarang kemungkaran, menuntut agar yang melarang terlebih dahulu mencegah dirinya. Itu agaknya yang menjadi sebab mengapa Lukman tidak memerintahkan anaknya melaksanakan ma'ruf dan jauhi yang mungkar, tetepimemerinthkannya, menyuruh dan mencegah. Disisi lain membiasakan anak anak melaksanakan tuntunan ini menimbulkan dalam dirinya jiwa kepemimpinan serta kepedulian sosial. ${ }^{17}$

\section{E. Penutup}

Berdasarkan hasil analisis tentang karakter manusia dalam al-Qur'an surat Lukman, maka dapat ditarik beberapa kesimpulan. Menurut al-Qur'an surat Lukman, ada beberapa karakter manusia yang meliputi karakter baik dan buruk,

\footnotetext{
16 Ibid, 120.

17 Ibid., 137.
} 
yaitu; a) Muhsinin, b) kesalehan, c) kepedulian tinggi, d) rendah hati, e) sombong, dan f) kufur nikmat. Nilai karakter dalam al-Qur'an surat Lukman ini meliputi beberapa nilai yaitu: a) iman/tauhid, b) birrul walidain, c) syukur, d) bijaksana, dan e) nilaisabar. Proses penanaman nilai karakter dalam al-Qur'an surat Lukman berdasarkan pada uraian pada bab sebelumnya dapat disimpulkan sebagai berikut: a) tujuan pendidikan yang termuat dalam surat Lukman adalah merupakan proses penanaman nilai dalam upaya untuk membentuk insan kamil, b) materi pendidikan Lukman terdiri dari akidah, syari'ah, dan akhlak, c) untuk menanamkan nilai keimanan, akhlak, dan syari'ah Lukman menggunakan metode maw'izdhah.

\section{Daftar Pustaka}

Abd al-Hayy al-Farmawi, al-Bidayah fi Tafsir al-Maudu'i(Mesir: Maktabah al-Jumhuriyah, 1977)

Abdul Mujib, Muhaimin,Pemikiran Pendidikan Islam(Bandung: Trigenda Karya,1993)
Al-Farmawi, Abd. Al-hayy, Metode TafsirMaudu'iy, SuatuPengantar, Terj: Suryan A. Jamrah, (Jakarta:Raja Grafindo, 1994)

Al-Fayumi Mursyi Ibrahim, Dirasah fi Tafsir al-Maudu'i (Cairo: Dar al-Taufiqiyah, 1980)

Al-Qur'andan Terjemahnya(Madinah al-Munawwarah: Mujamma' alMalik Fahd Thiba'at al-Mushhaf asy-Syarif, 1428)

Al-Qurtubi, al-jami' li al-ahkam alQur'an(Baerut: Dar Fikr, 1988).

Al-Suyuti Jalal al-Din, Lubab al-Nuqul fi al-Asbab al-Nuzul (Riwayat Turunnya Ayat-Ayat Suci alQur'an), Terj. M. Abdul Mujib, (Surabaya: Mutiara Ilmu, 1988)

Ambary, Muarif Hasan, Suplemen Ensiklopedi Islam(Jakarta, PT. Ictiar Baru Van Hoeve, 2001)

Azizy, Qodri, Membangun Integritas Bangsa(Jakarta: Renaisan, 2004)

Baidan Nashiruddin, Metodologi Penafsiran AlQuran(Yogyakarta: Pustaka Pelajar, 2000)

Cawidu Harifuddin, Metode dan Aliran Dalam Tafsir, Pesantren No.1/Vol.VIII 
Daryanto, 1998. Kamus Lengkap Bahasa Indonesia, Surabaya: Apollo, 1991)

\section{Departemen Agama RI,al- \\ Qur'an Tajwid dan \\ Terjemah(Surakarta:Ziyad, 2009)}

Dewan Redaksi Ensiklopedi Islam, Ensiklopedi Islam 3, (Jakarta: PT. Ichtiar Baru Van Hoeve, 1994)

Dosen Tafsir hadits Fakultas Ushuluddin UIN Sunan Kalijaga Yogyakarta, Studi Kitab Tafsir(Yogyakarta, Teras, 2004).

Federspiel Howar m, Kajian AlQur'an Di Indonesia:Dari Mahmud Yunus Hingga Quraish Shihab(Bandung: Mizan, 1996)

Imam Abu Hamid Muhammad Bin Muhammad al-Ghazali, Ihyâa' 'Ulûmiddzn, Juz I I I ,

(Beirut: Darul Fikr, 1999) Imam Machali, Ara Hidayat. Pengelolaan Pendidikan(Yogyakarta:Pustaka Educa, 2010)

Kaelan . Metode Penelitian Kualitatif Bidang Filsafat (Yogyakarta: Paramadina, 2005)

Katsir Ibnu, al-Bidayah Wa anNihayah, Terj. Lukman Hakim dan Ibnu Said, (Jakarta :Pustaka Azzam, 2012).

Kementerian

Pendidikan dan Kebudayaan RI, Pengembangan Pendidikan Budaya dan Karakter Bangsa(Jakarta: Kementerian Pendidikan Nasional, 2010)

Lickona, Thomas, Education of Character;How Our School Can Teach Respect And Responsibility(Aucland: Bantam Books, 1991)

Loeis Wisnawati, Nilai-nilai Pendidikan Islam dalam Tafsir Ahmad Musthafa Al-Maraghi: Studi Analisis terhadap Al-Qur'an Surat Al-Fiil,(Turats, Vol. 7, No. 1, Januari 2011)

Maragustam.

Mencetak Pembelajar Menjadi Insan Paripurna (Yogyakarta: Nuha Litera, 2010)

Moeleang, Lexy J., Metode Penelitian Kualitatif,(Jakarta: Rosda Karya 1991)

Muarif Hasan, Ambary, Suplemen Ensiklopedi Islam, (Jakarta: PT. Ictiar Baru Van Hoeve, 2001)

Muhammad 'Abd al-Malik Ibn Hisym, al-Sirah al-Nabawiyyah. Juz II, (Dar al- Fikr, t.th.) 
Muhammad Abdul Quasem dan Ahmad Kamil, Etika al-Gazali: Etika Majemuk D a l a m Islam(Bandung: Mizan, 1988)

Mursid,Kurikulum dan pendidikan Anak Usia Dini(Semarang: Akfi Media, 2009)

Nur Ichwan Mohammad, M. Quraish ShihabMembincang Persoalan Gender, (Semarang: RaSAIL Media Group,2013)

Nurcholis Madjid dalam Ridwan, Pengembangan Nilai-nilai Islami dalam Pembelajaran PAI di SMA, (El-Hikam Press, 2013)

Nurwadjah Ahmad, Tafsir Ayat-Ayat Pendidikan "Hati yang Selamat HinggaKisahLuqman"(Bandung: Marja, 2007)

Shihab, Quraish.Tafsir Al-Misbah, Pesan, Kesan, dan Keserasian Al-Qur'an vol.3, (Jakarta: Lentera Hati, 2011)

Shihab, Quraish, Membumikan alQur'an, Memfungsikan Wahyu Dalam Kehidupan, Jilid 2, cet 1, (Jakarta: Lentera Hati 2010)

Shihab, Quraish, Wawasan alQur'an: Tafsir Maudu'i Atas Pelbagai Persoalan Umat(Bandung: Mizan, 2003)

Shihab, Quraisy, Membumikan AlQur'an(Bandung: Mizan, 1992)
Suryabrata, Sumadi,Metodologi Penelitian, (Jakarta: Raja Grafindo Press, 2005)

Syafri, Ulil Amri, Pendidikan Karakter Berbasis Bahasa al-Qur'an, (Jakarta: Raja G r a n fi n d o Persada, 2012)

Undang-Undang SISDIKNAS,(UU RI No 20 Th. 2003) (Jakarta: Sinar Grafika, 2009)

Utsman Najati, Muhammad, adDirâsât an-Nafsâniyyah 'Indal 'Ulamâ'il Muslimzn, Cet. I. 1414 H, (Kairo, Darusy Syurûq, 1993)

Zaini Hasan, Tafsir Tematik Ayat-ayat Kalam TafsirAl-Maraghi(Jakarta: Pedoman Ilmu Jaya, , 1997)

Zaini Hasan, mengutip dari AliHasan al-Arid, Tarikh Ilm al-Tafsir wa Manahij al-Mufassirin(Sejarah dan Metodologi Tafsir(Jakarta: CV Rajawali Pers, , 1992)

Zamakhsyari, Imam, Tafsir alKasyaf, (Beirut: Dar al-Kutub al- 'Alamiyah, 1415H/1995)

Zeid, Mestika, Metode Penelitian Untuk Skripsi Dan Tesis Bisnis, (Jakarta: Raja Grafindo Persada, 2000)

Zuchdi, Humanisasi Pendidikan, (Jakarta: PT. Bumi Aksara, 2009) 